\title{
Reconstruction of dorsum of nose after excision of basal cell carcinoma
}

\author{
Anshuman Dwivedi ${ }^{1 *}$, Manmeet Kour ${ }^{2}$, Menka Gupta ${ }^{1}$ \\ ${ }^{1}$ Department of Oral and Maxillofacial Surgery, ${ }^{2}$ Department of Oral Medicine and Radiology, Rajnandini Cranio- \\ Maxillofacial and Esthetic Centre, Nirbhay Nagar, Agra, Uttar Pradesh, India
}

Received: 29 February 2020

Revised: 01 April 2020

Accepted: 02 April 2020

\section{*Correspondence:}

Dr. Anshuman Dwivedi,

E-mail: anshumandmaxfac@gmail.com

Copyright: ( $)$ the author(s), publisher and licensee Medip Academy. This is an open-access article distributed under the terms of the Creative Commons Attribution Non-Commercial License, which permits unrestricted non-commercial use, distribution, and reproduction in any medium, provided the original work is properly cited.

\begin{abstract}
Basal cell carcinoma, squamous cell carcinoma and melanoma are the most common malignant tumors of the face. The paramedian forehead flap is the standard reconstructive choice for closing large-sized defects of the distal half of the nose. A melolabial interpolation flap and bilobed or trilobed flaps are another option. The dorsal nasal (Rieger) flap is suitable at this location for the closure of small-sized defects, particularly when they are located medially. Here we are discussing an ulcus rodens case we observed in an elderly patient which was treated with a Rieger's flap.
\end{abstract}

Keywords: Basal cell carcinoma, Reiger's flap, Dorsum of nose

\section{INTRODUCTION}

Basal cell carcinoma (BCC) is the most common cancer in the world with an approximate probability of 20 to 30 percent overall lifespan. In recent decades, worldwide incidence rates have continued to rise 5-9 with a particularly large increase in young female populations, likely secondary to lifestyle-related use of indoor tanning and sun-seeking behavior. ${ }^{1}$ Basal cell carcinoma (BCC) accounts for about 70 percent of keratinocyte tumors representing 90 percent of all malignant skin conditions. ${ }^{2}$ The prevalence of BCC is approximately 2000 cases per 100000 population, and the morbidity varies depending on the geographical width and the age of the patients, with an increasing tendency for individuals over 50 years old. The BCC mainly affects photo-exposed areas, appears in the head in about 80 percent of patients and affects the skin of the cheeks and the nose in half. ${ }^{3}$ The tumor has slow progression and metastases are found in only 0.5 percent of the cases, but when treatment is neglected or inadequate it can lead to considerable local destruction and disfigurement. The main etiological factor responsible for $\mathrm{BCC}$ is the prolonged UV exposure mostly at the expense of (290-3200) mm strong UV rays. It results in the activation of proto-oncogenes in the keratinocytes and inactivation of tumor suppressant genes. The high doses of UV light cause free oxygen radicals, which together with the decreased antioxidant protection system contribute to various processes of degeneration including carcinogenesis. ${ }^{4}$ The UV rays cause the formation of pyrimidine dimers and the loss of heterozygosity of both the tumor-suppressive (protective) genes TP53 and PTCH, resulting in BCC in selected tetra nucleotide combinations of the coding genes as a sequence of microsatellite instability. ${ }^{5}$ Here we are discussing an ulcus rodens case we observed in an elderly patient which was treated with a Rieger's flap.

\section{CASE REPORT}

Here we present a case of 85 years normotensive non diabetic man, farmer by occupation with chief complaint of nodular friable growth over dorsum of nose since, 2 years, gradually progressive to current size which was associated with itching and bleeding on touch. It was not related to difficulty in breathing, with no discharge from growth. There was no history of preceding trauma as well as loss of appetite and weight. Patient was averagely built with stable vitals, on general examination. On local examination the lesion was $2 * 1 \mathrm{~cm}$ nodular firm growth 
over nasal dorsum, which was roughly oval, erythematous, slightly tender, bled on touch with minimal surrounding induration. No palpable lymph nodes during clinical examination. Patient was investigated to detect the basal cell carcinoma and after obtaining the consent of the patient, underwent the wide local excision with Rieger's flap cover over the area.

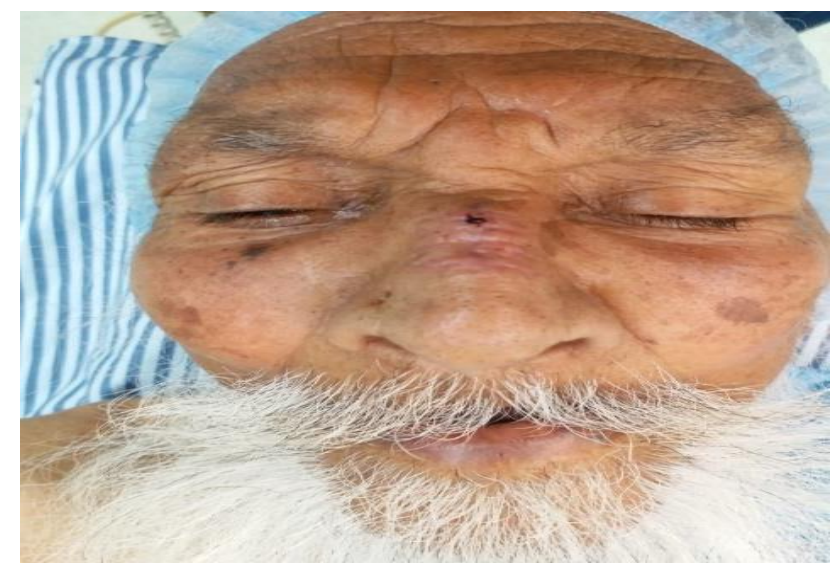

Figure1: Basal cell carcinoma on the bridge of the nose measuring $2 * 1 \mathrm{~cm}$.

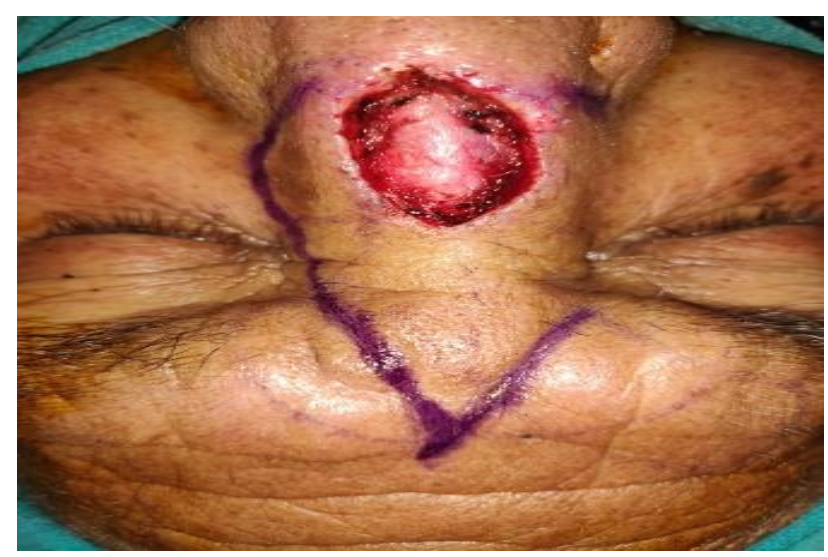

Figure 2: Wide excision of the lesion with $3 \mathbf{m m}$ margin and marking of Reiger's flap.

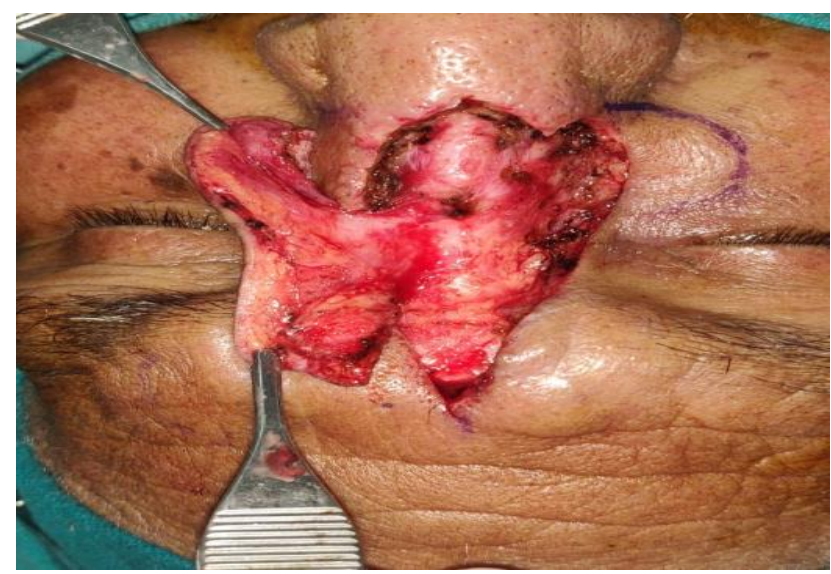

Figure 3: Complete mobilization of the flap to achieve maximal tissue movement.

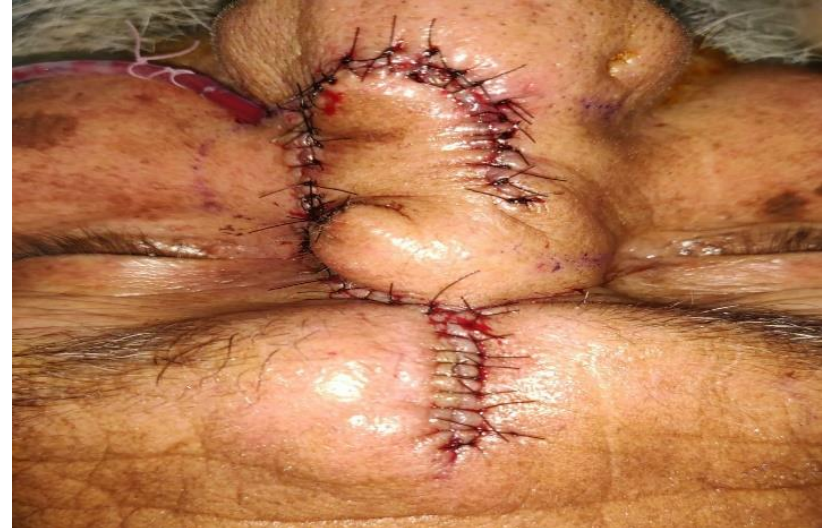

Figure 4: Frontal view, closer with 5-0 ethilon non absorbable suture material.

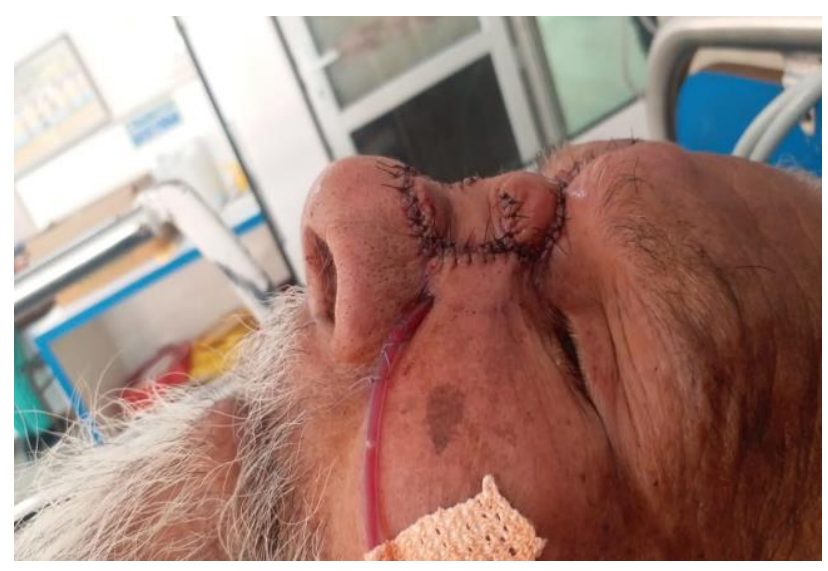

Figure 5: Left lateral view of the patient.

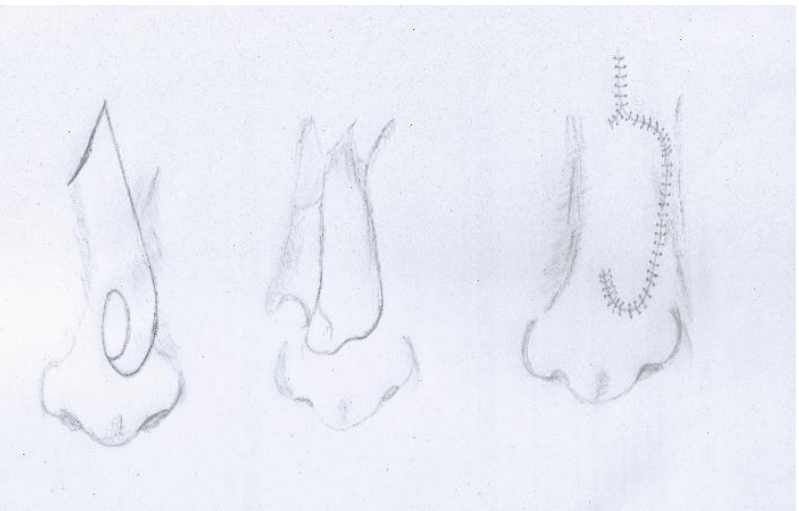

Figure 6: Sketch illustrating the modified rotation

flap of the nasal dorsum beginning in the upper portion of the defect with lengthening of the leading edge of the flap, which provides tissue from the lateral side of the nose.

\section{Surgical procedure}

The lesions were removed with a safety margin of $3 \mathrm{~mm}$ following local anaesthetic injection. The flap was outlined in the usual manner firstly. A deep sweeping curvature of the free edge of the flap was performed for 
the defects involving the dorsal portion. The free edge deep arc provided coverage for donor skin. In the skeletonizing plane the flap was incised and undermined all over the defect. Undermining at nasion and glabella became more superficial and the back-cut at glabella provided essential mobility for the flap. In cases requiring further advancement or rotation, the skin incision may be lengthened to medial canthal ligament level. The lateral incisions were placed at the naso-facial junction making sure the nasal sidewall subunit was not violated. The flap was uplifted and rotated into place. The distance from the base of the glabella to the superior tip of the glabellar portion of the flap should be approximately 1.5 to 2 times the vertical height of the nasal defect to ensure adequate tissue movement. Here, the lines directed toward the contralateral medial canthus, creating a $30^{\circ}$ to $45^{\circ}$ angled back cut. Incisions can be made prior to undermining. Alternatively, prior to incisions, undermining bluntly from the defect toward the glabella may be accomplished in the loose areolar plane just below the superficial musculoaponeurotic system of the nose. After flap undermining, incisions are completed in the lines previously drawn. Blunt dissection and undermining beneath the musculature of the nasal sidewall is then completed until the entire flap is lifted from the periosteum and perichondrium. Rieger emphasized completely mobilizing the pedicle of the flap down to the epicanthal ligament as well as to the contralateral nasofacial sulcus beneath the transverse nasalis muscle. This is necessary to achieve maximum flap mobility and tissue movement. The myocutaneous flap is then advanced and rotated into the primary surgical defect and primarily closed with 5-0 ethilon. Post-operatively a negative pressure drain was placed immediately which was removed after 48 hours.

\section{DISCUSSION}

In 1967 Rieger popularized the surgical reconstruction using the dorsal nasal flap. ${ }^{6}$ The dorsal or Rieger flap is considered basically a rotational flap of the nasal dorsal skin. ${ }^{7}$ Originally designed as a random flap, and transformed into an axial flap, $2 \mathrm{~cm}$ diameter lesions were recommended. ${ }^{6}$ Some modifications to the procedure have been suggested since it was first described, thus improving its applicability. These concern the lateral design as well as the proximal portion next to the glabella. The glabella shape is of great importance in flap design. Some patients have vertical wrinkles and other patients have a very prominent nasal bridge with excess tissue that facilitates, and even marks, where a horizontal fold is to be incised. ${ }^{7}$ Flaps that rotate or transpose around a cutaneous pedicle's pivotal points are restricted by that tissue base. The complexities of flap tethering can be predicted by changing the flap dimensions to avoid unwanted degrees of stress or tissue displacement. The novelty of this procedure lies in the lengthening of the flap rotation leading edge, which may provide tissue from the adjacent nasal skin, cheek, or groove to close the defect. Indeed, the key to designing these flaps is to simply close the donor zone beyond the nasal dorsum, either directly or by releasing incisions that allow the cheek to slightly advance. ${ }^{8}$ Normally, a remnant of skin allows direct closure along a physiological fold at these anatomic sites after large lesions have been excised. The texture and color of this hairless skin is similar to that of the nose, and though it may contain fewer sebaceous glands in males, it hardly affects the final cosmetic result. Often, the advancement of the cheek's skin or the nasofacial groove is insufficient to close large nose defects; advancement alone may pull asymmetrically on the nostril or cause a trap-door action. ${ }^{9}$ In contrast, rotation of the nasal dorsum, combined with extension of the rotating flap's leading edge, results in a much more aesthetically acceptable result. ${ }^{10}$ Classically, a 2 stage paramedian forehead flap is used for closing defects larger than $2.5 \mathrm{~cm}$ in diameter on the nasal pyramid; it has a more complex design and is more difficult to execute. ${ }^{7}$ We suggest the paramedic forehead flap should be reserved for reconstructing defects of a larger size or defects affecting the nasal pyramid's full thickness.

\section{CONCLUSION}

It is important to maintain the highest level of nasal reconstruction expertise in order to give patients the best aesthetic and functional results. When performed on properly selected patients, the Rieger flap is an aesthetically predictable, one-stage procedure.

Funding: No funding sources

Conflict of interest: None declared

Ethical approval: Not required

\section{REFERENCES}

1. Lanoue J, Goldenberg G. Basal Cell Carcinoma: A Comprehensive Review of Existing and Emerging Nonsurgical Therapies. J Clin Aesthet Dermatol. 2016;9(5):26-36.

2. Totonchy M, Leffell D. Emerging concepts and recent advances in basal cell carcinoma. F1000 Research. 2017;6:2085.

3. Ofaiche J, Lopez R, Berard E, Andre A, Livideanu BC, Meresse T, et al. Surgical Treatment of Facial Basal Cell Carcinoma: Patient-Based Assessment of Clinical Outcome in a Prospective Cohort Study. Dermatology. 2016; 232(5):550-7.

4. Wollina U, Langner D, Bennewitz A. Basal cell carcinoma of the outer nose: Overview on surgical techniques and analysis of 312 patients. J Cutaneous Aesthetic Surg. 2014;7(3):143.

5. Dourmishev L, Rusinova D, Botev I. Clinical variants, stages, and management of basal cell carcinoma. Indian Dermatol Online J. 2013;4(1):12.

6. Redondo P, Bernad I, Moreno E, Ivars M. Elongated Dorsal Nasal Flap to Reconstruct Large Defects of the Nose. Dermatol Surg. 2017;43(8):1036-41. 
7. Maloney M. The Rieger flap for nasal reconstruction. J of the American Acad Dermatol. 1996;34(3):502.

8. Rieger RA. A local flap for repair of the nasal tip. Plast Reconstr Surg. 1967;40:147-9.

9. Shende K, Rao J. Overview of local flaps of the face for reconstruction of cutaneous malignancies: Single institutional experience of seventy cases. J Cutaneous Aesthetic Surg. 2016;9(4):220.
10. Eren E, Beden V. Beyond Rieger's original indication; the dorsal nasal flap revisited. J Craniomaxillofac Surg. 2014;42:412-6.

Cite this article as: Dwivedi A, Kour M, Gupta M. Reconstruction of dorsum of nose after excision of basal cell carcinoma. Int J Otorhinolaryngol Head Neck Surg 2020;6:1005-8. 